\title{
Rompimento do modelo epistemológico mimético
}

\author{
Antônio Jackson de Souza Brandão*
}

\begin{abstract}
Resumo
A mimese como modelo epistemológico teve seu apogeu no século XVII, para entrar em declínio nos séculos seguintes. Com seu rompimento, perderam-se os modelos de representação que também permearam a cultura ocidental por séculos e, a partir do século XIX, a subjetividade assume o papel preponderante na arte. Mais do que uma mudança na percepção da arte, verificou-se uma mudança na percepção do mundo que cerca o homem, cuja grande influência deveu-se à fotografia.
\end{abstract}

\section{Palavras-chave}

Mimese. Iconologia. Representação. Seiscentismo. Iconofotologia.

\section{De Lessing aos românticos alemães}

Romper barreiras: uma característica marcante da humanidade ao longo de sua existência, seja transportando pedras gigantescas - para construir pirâmides -, seja superando a velocidade do som - numa aeronave. Exemplos não faltam, o próprio ser humano pode ser considerado uma barreira superada dentro da natureza: possuidor de uma compleição frágil, reunia condições que dificultariam sua sobrevivência, num ambiente hostil, cercado por seres muito mais fortes e, aparentemente, mais

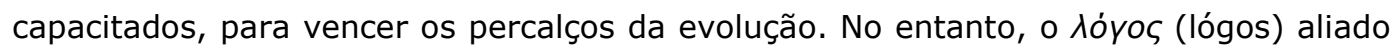
à $T \varepsilon \dot{x} u \eta$ (téchne) fizeram a diferença, fazendo com que a fragilidade se convertesse em solidez.

Porém, a barreira transposta que importa destacar neste artigo não está nem num passado remoto, tampouco num tão próximo, mas refere-se ao rompimento da

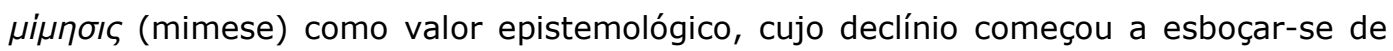
forma incipiente no século XVIII, aprimorou-se no século XIX, e efetivou-se no século $\mathrm{XX}$.

A partir dessa ruptura, caberia somente ao artista demonstrar seu gênio criador, já que sua obra artística - seja pictórica seja poética - não estaria mais atrelada à

${ }^{*}$ Dr. Profesor - FIVR/UNISEPE-SP. 
tradição, mas à expressão. Além disso, rompeu-se a relação estabelecida por essas duas artes, cujo princípio norteador foi o Ut pictura poesis. Este foi posto em xeque, já no século XVIII, por Lessing em sua obra Laocoonte: ou sobre as fronteiras da pintura e da poesia, quando, ao demarcar as fronteiras entre poesia e pintura, antecipa o rompimento entre as duas expressões artísticas, cuja interrelação havia sido harmônica desde o Renascimento, como demonstram as iconologias e os emblemas. ${ }^{1}$ (Cf.: BRANDÃO, 2010a, p. 129)

Lessing delimita o campo de atuação tanto da imagem quanto da escrita a dois aspectos não intercambiáveis: o tempo e o espaço. Aquele ficaria a cargo da poesia, este da pintura. Esta, por exemplo, tem de utilizar um único momento da ação em suas composições. Deve, portanto, escolher o momento mais expressivo a partir do qual se torna mais compreensível o que já se passou e o que se seguirá. (Cf.: LESSING, 1998, p. 194) Dessa forma, a pintura deve renunciar totalmente ao tempo. Assim, ações progressivas não podem fazer parte de seu objeto; ela deve, portanto, contentar-se com ações uma ao lado da outra ou com meros corpos que sugerem uma ação por meio de suas posições. (Cf.: ibidem, p. 190)

À escrita, caberia desenvolver as ações que vão sendo pintadas à medida que o leitor vai lendo (Cf.: ibidem, p. 195), em um ato contínuo de protensão e retenção, afinal "não somos capazes de apreender um texto num só momento" (Iser, 1999, p. 11), como fazemos com um objeto qualquer. Isso porque este, enquanto objeto de percepção, se evidencia como um todo, já que nos encontramos diante dele; o texto, por sua vez, apenas pode ser apreendido como "objeto" em fases consecutivas da leitura, afinal estamos dentro dele, por meio da leitura. (Cf.: ibidem, p. 12)

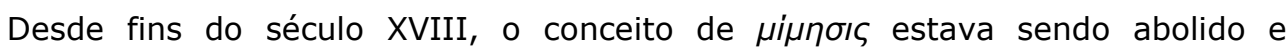
recusado pelos jovens românticos alemães que visavam não só à plena liberdade na criação artística como também a uma nova afirmação da arte, não mais voltada, especificamente, à mera imitação da natureza, mas à produção e à reprodução do espírito. Friedrich Wilhelm Schelling, por sua vez, propõe não a negação total do princípio mimético, mas sua transformação (Cf.: GONÇALVES in DUARTE (org.), 2001, p. 289-293); Friedrich Schlegel, por sua vez, via no Romantismo uma transformação estética definitiva, cujo sentido principal seria o de libertar a arte não só de sua função mimética em relação à natureza, mas também de sua forma inferior de apreensão da verdade a partir da consolidação da ideia de que a arte é produzida por uma subjetividade livre e naturalmente criadora, ao mesmo tempo intelectual e intuitiva, consciente e inconsciente de e em sua criação artística. (Cf.: ibidem, p. 289)

Assim, quanto mais as artes pictográfica e poética distanciavam-se, aumentava, naturalmente, a independência uma da outra. Já no século XIX, é possível verificar que, na pintura, se inicia um verdadeiro exorcismo de elementos literários em seu processo criativo, cujo encetamento dá-se com o Impressionismo e que culmina na pintura abstrata e/ou conceitual. Por meio da ruptura com a tradição convencional de linguagem e textualidade (iconografia), os pintores das diferentes tendências

${ }^{1}$ Evidentemente, a relação entre poesia e pintura não tem início no Renascimento, mas na Antiguidade. 
modernistas se concentraram no desenvolvimento do puramente visual. (Cf.: SCHØLLHAMMER, 2001, p. 30-31)

Simultaneamente à quebra do domínio mimético na arte, verifica-se o distanciamento da obra artística dos modelos preestabelecidos pelos tratados iconológicos e emblemáticos. Estes foram simplesmente esquecidos, resultando daí o fato de a obra artística seiscentista, por exemplo, ter sido considerada obscura e repleta de detalhes poluidores e desnecessários. Aquilo, porém, que se considerava supérfluo nesse fazer artístico, corresponderia ao desconhecimento de sua codificação, ou seja, ao óbvio vácuo cultural diacrônico.

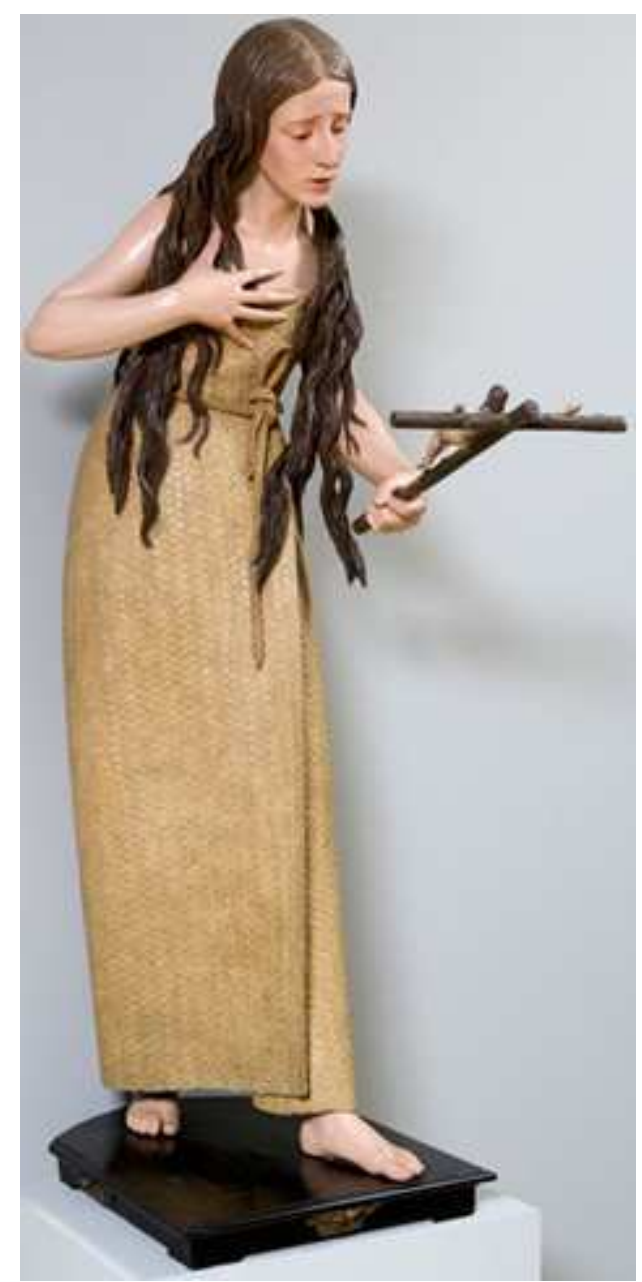

Figura 1 - Maria Madalena, de Pedro de Mena, 1664

Para ilustrar esse ostracismo a que se relegaram esses fazeres artísticos, tomemos como exemplo a obra Maria Madalena, do espanhol Pedro de Mena (fig. 1). Tendo-a como paradigma, será possível compará-la a outras cujo objeto temático é a representação de Maria Madalena - e visualizar suas diferentes abordagens ao longo da história. Assim será possível vislumbrar, mesmo que de forma superficial, seu esmaecimento iconológico. 


\section{O esmaecimento iconológico}

Diante da obra de Pedro de Mena, pode-se ter a impressão de se estar diante de uma representação única e original, no entanto se a cotejarmos com outras do mesmo período, é possível verificar similitudes entre suas contemporâneas, devido a certas regularidades com que os artistas do período abordavam temas afins. Dessa maneira, verifica-se que essas obras não eram nem singulares, nem originais, afinal seguiam-se regras específicas de representação, definidas por manuais e tratados preestabelecidos, o que resultava em obras artísticas análogas: modificavam-se as feições do representado, não o modo de representação. (BRANDÃO, 2010a, p. 17ss)

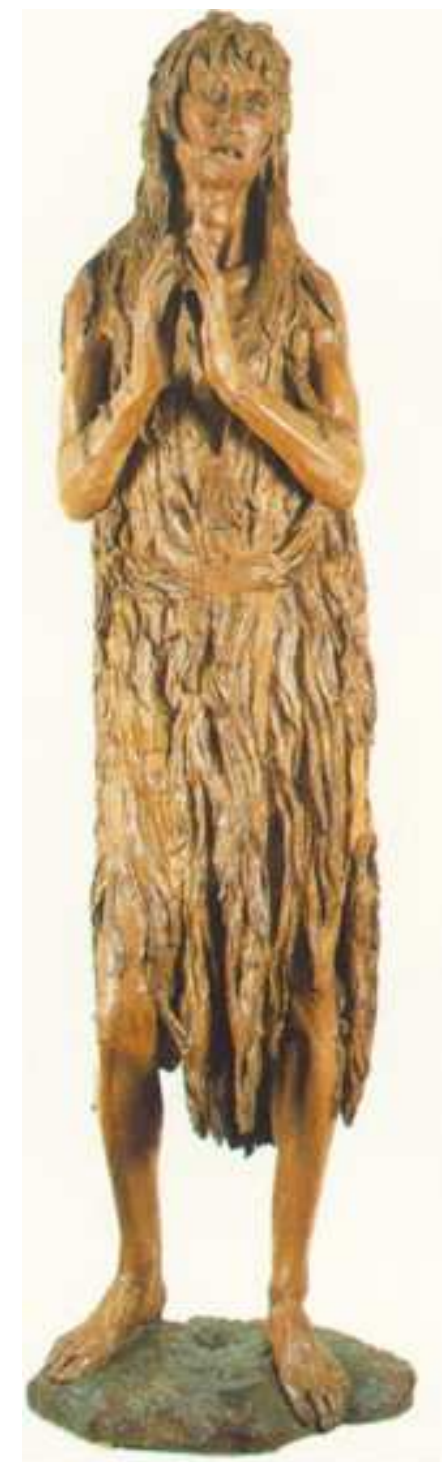

Figura 2 - Santa Maria Madalena, de Donatello, (1453-55)

Com o esmaecimento e desaparecimento das preceptivas retóricas que regiam os séculos XVI, XVII e XVIII, desaparece também o emprego de certos elementos icônicos largamente empregados naquele período que passariam aos séculos 
posteriores ou sendo ignorados ou empregados como mero "adorno" pictórico, como se vê com o emprego do crânio na figura 3.

Na obra escultórica renascentista do italiano Donatello (fig. 2), Maria Madalena é apresentada como uma mulher velha, "de rostro macilento, revestida com ropas tristísimas y pobres [...], mirando atentamente a los Cielos" (Ripa, 1987, p. 190); o que, numa leitura iconológica, representaria, na Iconologia de Cesare Ripa, um sinal de "Penitência".

No entanto, suas mãos, à diferença da obra de Mena, estão juntas, por isso podem indicar, segundo a iconologia vigente:

a) a "Terceira Bem-aventurança" (ibidem, v. 1, p. 150): Felizes de vocês que agora choram, porque hão de rir. (Lc 6, 21b) Já que ela, agora velha, pode receber a recompensa que tanto almeja: reencontrar-se com o Mestre, afinal já chorara demasiadamente durante sua vida;

b) "Meditação espiritual", pois con las manos juntas, una contra otra, simbolizándose con ello el efecto de la devoción y la humildad que se encuentra en las personas, continuando y ejerciendo de este modo la medida y alcance de la Meditación Espiritual. (ibidem, p. 64)

Por outro lado, o aspecto desolador da imagem também poderia levar o leitor seiscentista a lê-la, inclusive, como indicação de Melancolia:

Mujer vieja, muy triste y dolorida, vestida con paño basto y sin ningún ornamento. [...]

Se pinta anciana por ser los jóvenes de ordinario más alegres, y los viejos por el contrario melancólicos, como dice Virgilio [...].

Va mal vestida y careciendo de adornos, a semejanza de los árboles cuando se ven sin hojas y sin frutos; pues nunca levanta su ánimo al melancólico hasta el punto de procurarse las necesarias comodidades, a fin de proveer o rehuir los males que imagine le acechan (ibidem, p. 65).

O mesmo não se pode dizer da Madalena (fig. 3) do também italiano Antonio Canova, retratada como uma mulher jovem, bonita e sensual que, sentada sobre as pernas posta-se numa atitude, segundo nosso ponto de vista, de adoração, de entrega, de oração. No entanto, a disposição de seu corpo e de seus gestos não corresponderia a nenhuma das ações enumeradas anteriormente, pelo menos segundo os modelos iconológicos dos séculos XVI ao XVIII.

Ao se representar Oração, pintava-se uma mulher "de rodillas y con los brazos abiertos para mostrar la reverencia que se debe tener para con Dios, y de modo particular si se estuviese rezando" (Ripa, op. cit., p. 160). A atitude de manter os braços abertos, demonstrando oração é muito antiga e há vários exemplos no mundo protocristão como na igreja de Santos Giovanni e Paolo, em Roma (séc. IV); a imagem de Próculo na catacumba de S. Gennaro, em Nápoles (séc. V); o mosaico da entrada da igreja de São Demétrio, em Tessalônica (séc. VI); a pintura mural no Monastério de São Jeremias, em Saqqara, Egito (séc. VII), entre outros. (Cf. BELTING, 2009, p. 109119) 


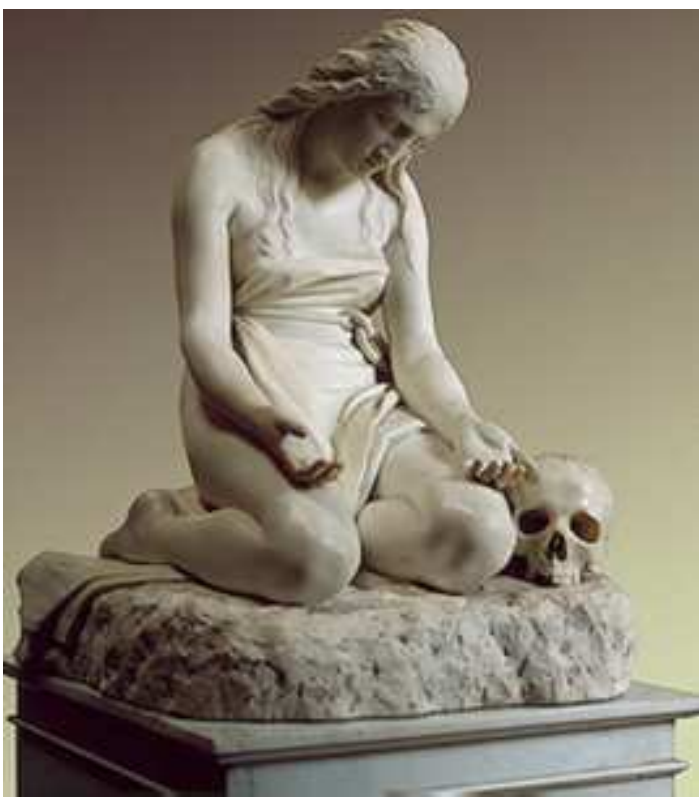

Figura 3 - Maria Madalena penitente, de Antonio Canova, 1809

Além dos braços abertos, a cabeça deveria estar voltada para o céu, o que difere da oba de Canova:

\begin{abstract}
El llevar levantada la cabeza, mirando hacia la luz que antes dijimos, claramente nos muestra [...], que la Oración no viene a consistir sino en cierta elevación o sublimidad de la mente y excitación de nuestro afecto, de manera que el hombre [...] se sincera con Dios [...]. (RIPA, op. cit., p. 160)

Os leitores do século XVII, por exemplo, até poderiam ler os olhos baixos de Madalena como sendo sinal de humildade:

Mujer con traje blanco; lleva los ojos bajos, mientras sostiene en brazo un tierno Corderillo. [...]

Ha de ir vestida de saco, mientras que pisote a algunas ropas de aspecto
\end{abstract} valiosísimo. (ibidem, p. 499)

É até possível verificar que a Madalena de Canova possui um vestido cingido por uma corda à semelhança da de Pedro Mena, e que esteja sobre algunas ropas: mas esse sentar-se sobre as pernas não demonstraria a devida "reverencia que se debe tener para con Dios" (ibidem, p. 160).

O único sinal visível que remeteria à Penitência seria o crânio ao lado da jovem, conforme os modelos provenientes da emblemática, empregados, provavelmente, como mero adorno, pois os outros elementos essenciais - o cilício, o crucifixo e o estar de joelhos - foram ignorados.

Vê-se que os leitores, a partir do século XIX, querem vislumbrar a plasticidade da obra, interessam-se por sua beleza estética, sua criatividade, sua subjetividade, enfim como o tema foi abordado. Os tempos já são outros e mesmo que os elementos iconológicos apareçam na obra sempre serão meros adornos como na figura 4. É provável que grande parte dos contemporâneos de Francesco Hayez restringirá sua leitura imagética aos campos pré e iconográfico (Cf. PANOFSKY, 2004, p. 47-87), mas 
dificilmente adentrarão no iconológico. Isso porque este referencial ao ser esquecido, foi coberto por um velame que encobre grande parte de seu caráter sígnico, logo não será mais possível visualizar a ideia original, nem imaginar como teria sido a concepção original da obra, como na imagem de Lefevre.

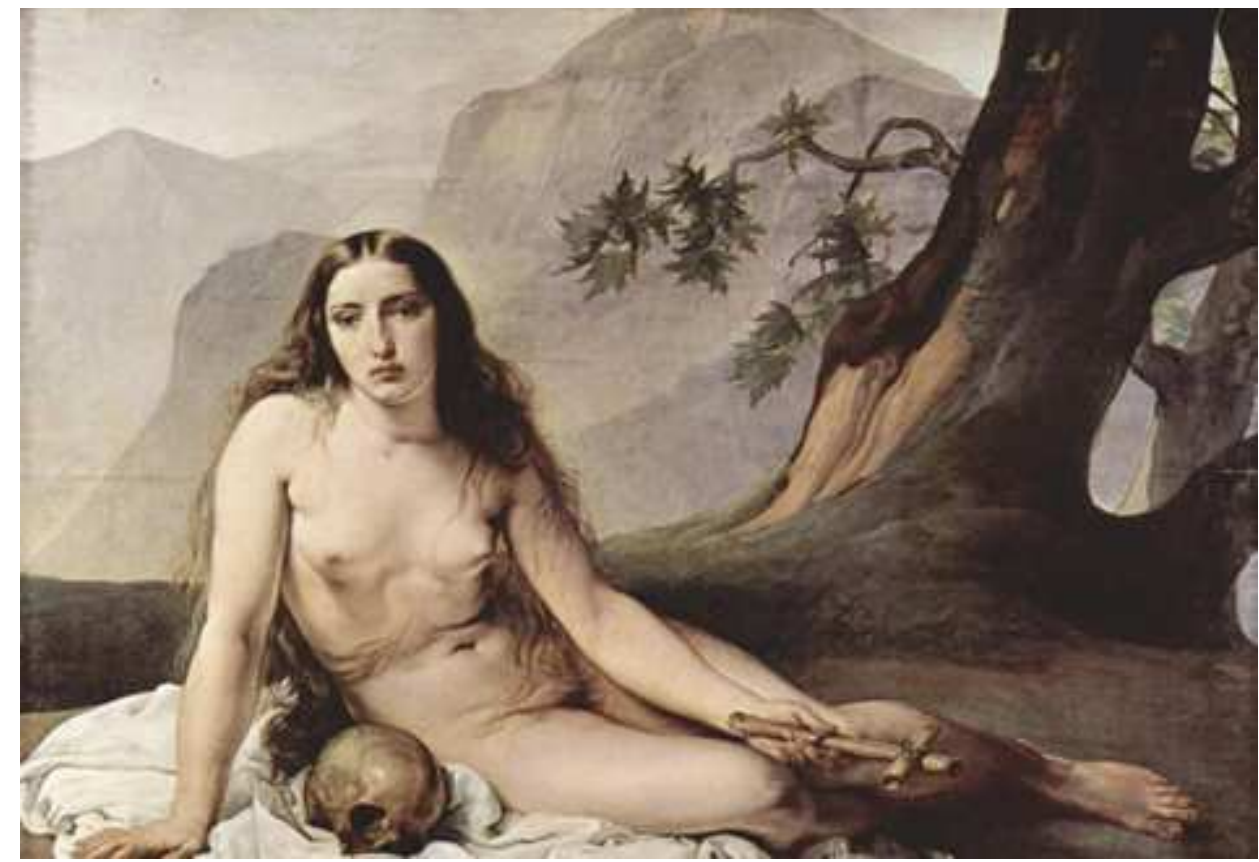

Figura 4 - Maria Madalena penitente, De Francesco Hayez, 1825

Esta de sacra - a representação de uma santa da Igreja católica -, torna-se pagã, pois poderia ser a representação de qualquer divindade greco-romana: eis o fruto da liberdade estética e da criatividade, cuja escolha fica a cargo do artista, demonstrando que o poder de criação está, agora, em suas mãos.

Essa liberdade criadora e a possibilidade de experimentação no campo das artes seriam impensáveis para o homem dos Seiscentos, o qual se encontrava atado à $\mu i \mu \eta \sigma \varsigma$ e sob a influência das iconologias que circulavam no período. É evidente que esse status quo representava um empecilho à criatividade, pelo menos nos moldes propagados pelo Romantismo, já que se cerceava a liberdade criadora. Não é de se estranhar, portanto, a obstinação de Schlegel e dos românticos alemães, para quem a arte tinha de ser produzida por uma subjetividade livre e criadora, ou seja, por um eu que fugisse de modelos preestabelecidos, da mera imitação, e que se voltasse ao individual, ao emotivo, em detrimento do racionalismo coletivo a que a arte estava submetida.

O século XIX libertou-se da $\mu i \mu \eta \sigma \varsigma$, não das imagens. Estas expandiram seu campo de ação para além das fronteiras da emblemática e das iconologias - e de toda a tradição da Antiguidade que a acompanhava -, como modelos epistemológicos e paradigmáticos, permeando-se de outros elementos inimagináveis, afinal adentraram

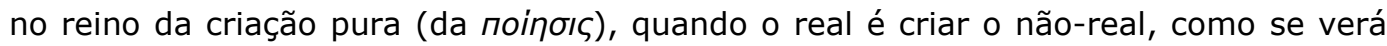


na arte contemporânea com o rompimento total da relação imagem-texto que havia sido proposta desde a Renascença. Apesar desse rompimento mantiveram-se alguns resquícios, não mais como um preceito a ser obedecido, mas sob a direção e o domínio do artista.

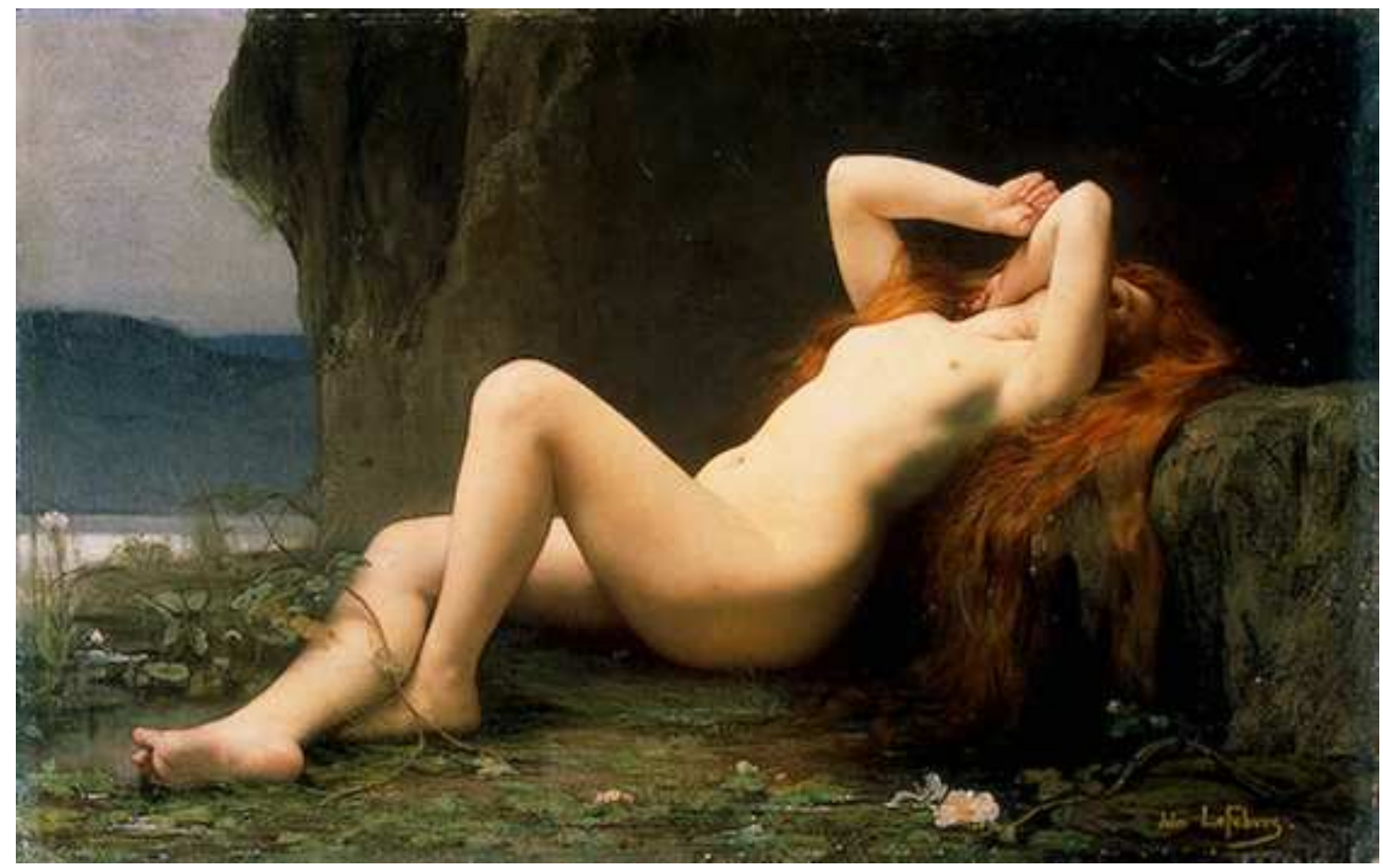

Figura 5 - Maria Madalena na gruta, de Jules Josef Lefevre, 1876.

Em $A$ vida de Maria Madalena (fig. 6), Salvador Dalí mescla elementos surreais com os da Renascença - os mesmos das iconologias e da emblemática -, revelados pela figuração dessa tela, utilizadas ao bel-prazer do pintor, não por imposição.

Por isso, quando se afirma que houve um rompimento na interrelação imagemtexto, princípio motor da arte seiscentista, não se quer dizer que a mesma tenha deixado de existir ou mesmo que inexista em nossos dias; pelo contrário, essa relação se expandiu de forma tão explosiva nas ciências humanas, a ponto de a imagem, para alguns teóricos como o estadunidense W. J. Thomas Mitchell, emergir como paradigma no seio dessas mesmas ciências:

a relação entre literatura e imagem já não se limita ao encontro singular da obra literária com a obra visual, mas deve ser vista na perspectiva mais ampla dos estudos das visibilidades, da cultura visual e do desenvolvimento tecnológico de novas formas de representação visual. (MITCHELL, apud SCHØLLHAMMER, p. 31) 


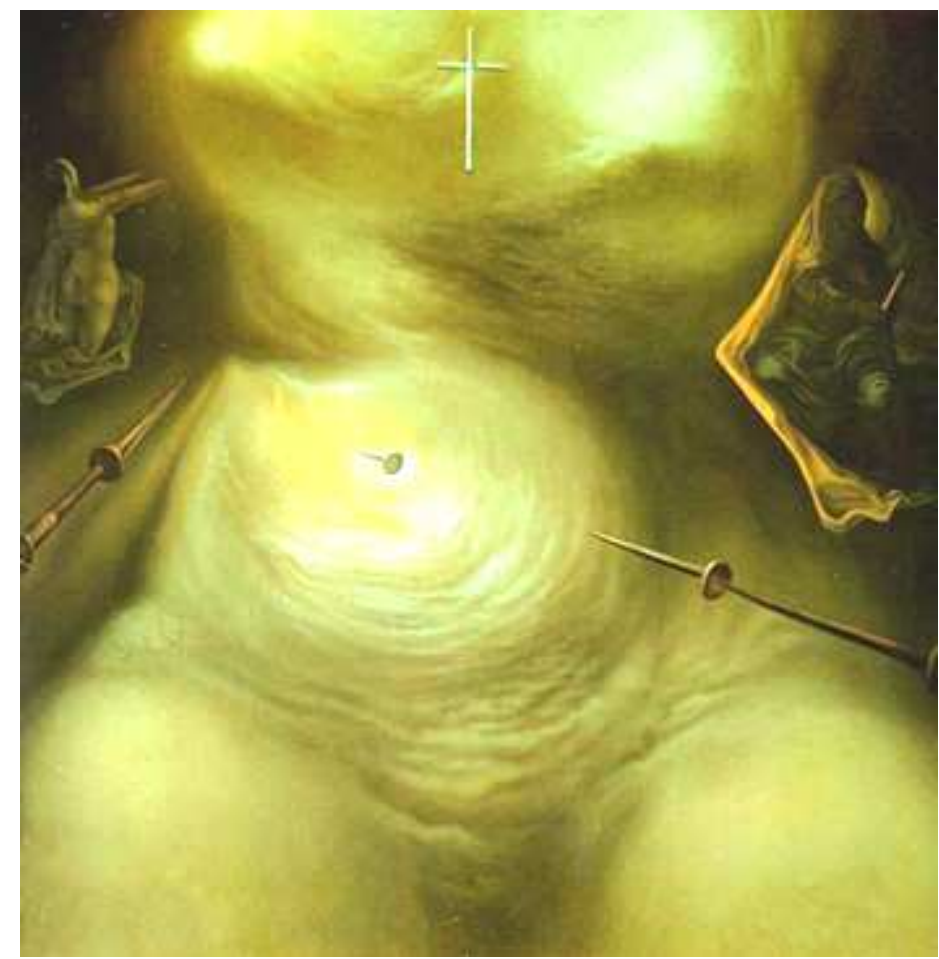

Figura 6 - A vida de Maria Madalena, de Salvador Dalí, 1960

\section{A questão do estilo}

Dessa forma, poderíamos inferir, por mais paradoxal que possa parecer, que a libertação da pintura em relação à poesia (e vice-versa) foi momentânea; quer dizer,

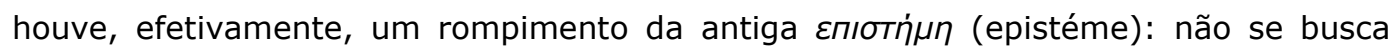
mais a representação fidedigna da natureza, da realidade ou, como diz o teórico alemão Hans Ulrich Gumbrecht: "os textos literários escritos atualmente voltaram a apresentar "mundos" a seus leitores" (GUMBRECHT, apud FARINACCIO, 2004, p. 11) 2, ou seja, autores como Gabriel García Márquez (Cem Anos de Solidão) ou Umberto Eco ( $O$ Nome da Rosa) não descrevem em suas obras nem a realidade típica caribenha em um, nem o mundo medieval real em outro, sequer propõem ou reivindicam para si fidelidade a quaisquer referentes preexistentes (ibidem, p. 12), situação totalmente oposta à dos modelos clássicos que serviram de modelos para os autores dos Seiscentos, para quem a obra deveria ser realista, ou seja, basear-se no real sem, contudo, se preocupar com a história ${ }^{3}$, afinal aqueles autores desconheciam a ideia de forças históricas (Cf.: AUERBACH, 2004, p. 28), talvez por isso os textos clássicos, como os de Homero, pareçam-nos sempre lendários, desconexos, irreais apesar de não os serem totalmente:

\footnotetext{
${ }^{2}$ Em relação ao Realismo do século XIX, por exemplo, citado adiante: Mas diferentemente do Realismo do século XIX, eles não estão obcecados com a preocupação de dignificar estes mundos literários pela insistência sobre o seu status de representações. (Gumbrecht, apud Farinaccio, p. 11).

${ }^{3}$ Enquanto ciência que estuda a ação do homem ao longo de um tempo determinado.
} 
Enquanto ouvimos ou lemos a sua estória, é-nos absolutamente indiferente saber que tudo não passa de lenda, que é tudo "mentira". [...] Homero [...] não tem necessidade de fazer alarde da verdade histórica do seu relato, a sua realidade é bastante forte; emaranha-nos, apanha-nos em sua rede, e isto the basta. Neste mundo "real", existente por si mesmo, no qual somos introduzidos por encanto, não há tampouco outro conteúdo a não ser ele próprio; os poemas homéricos nada ocultam, neles não há nenhum ensinamento e nenhum segundo sentido oculto. (ibidem, p. 10)

Auerbach demonstra-nos, por exemplo, a diferença de enfoque entre o texto homérico e o bíblico: aquele visava à realidade - por meio da imediatez, fluidez e simplicidade narrativa - enquanto este, exclusivamente, à "verdade", devido a seu caráter religioso e a sua "pretensão à universalidade histórica" (Cf.: ibidem, p. 13). Um texto pretende "agradar" e "encantar" - como o homérico -, enquanto um outro "doutrinar" e "prometer" - como no bíblico, em especial o Antigo Testamento -, daí seu caráter obscuro e metafórico (Cf.: ibidem, p. 12) que perpassará a Antiguidade e será reaproveitado na Idade Média, no Renascimento e no Barroco, como atesta o gênero emblemático com suas preceptivas moralizantes.

Como herdamos, no Ocidente, tanto a cultura helênica quanto a hebraica, podemos ser tentados a inverter o fim a que cada gênero se propõe, ou seja, queremos ler a "seriedade" e a "realidade" num texto bíblico; ou, de uma forma doutrinária e fantástica o texto clássico; ou ainda, acreditar encontrar a "verdade" em ambos. Evidentemente, não conseguiremos nenhuma das proposições apresentadas. Ainda citando Auerbach, este nos mostra que

$\mathrm{Na}$ literatura moderna, qualquer personagem, seja qual for o seu caráter ou posição social, qualquer acontecimento, fabuloso, político ou limitadamente caseiro, pode ser tratado pela arte imitativa de forma séria, problemática e trágica, e isto geralmente acontece. Na Antiguidade isto é totalmente impossível. (ibidem, p. 27)

Essa impossibilidade é devida à separação dos estilos, ou seja, para nós qualquer questão representada via literatura ou via pintura, independente de a personagem concebida pertencer a uma classe social alta ou baixa, pode-nos levar à comoção, à meditação. Isso nunca ocorreria com os antigos, para quem a representação de

qualquer ofício, posição social quotidiana - comerciantes, artesãos, camponeses, escravos -, qualquer cenário quotidiano - casa, oficina, loja, campo -, qualquer costume quotidiano - casamento, filhos, trabalho, alimentação - numa palavra, o povo e sua vida (AUERBACH, op. cit., p. 27)

jamais poderiam ser, literalmente, levados a sério, pois nunca abandonam o campo do cômico. Um indivíduo assim representado nunca teria vez numa sociedade em que havia uma separação clara entre o que poderia ser representado pela classe elevada e por aquelas consideradas inferiores, além disso, por não existir o conceito da ação de forças históricas, as pessoas eram vistas a partir de outros valores: os antigos interessavam-se, sobretudo, pela problemática moral - que só residiria na aristocracia -, por isso o individual prevalecia sobre o coletivo: 
A crítica dos vícios e dos excessos, por mais que sejam muitas as pessoas retratadas como viciosas ou ridículas, coloca o problema de forma individual, de modo que a crítica da sociedade nunca leva ao desvendamento das forças que o movem. (ibidem, p. 28)

Essa mesma separação estendia-se para aquilo que consideravam belo e feio. Restringiam-se, às classes inferiores, o feio e o grotesco (baixo estilo); à classe elevada, o belo e o virtuoso (estilo elevado). A esse respeito, diz-nos um teólogo do século XVII:

\begin{abstract}
toda a intenção de um poeta, toda a finalidade do seu trabalho, é que sejamos, como o seu herói, apaixonados pelas belas pessoas, que as sirvamos como divindades; em uma palavra, que Ihes sacrifiquemos tudo, afora, talvez a glória, cujo amor é mais perigoso que aquele que temos pela própria beleza. (ibidem, p. 351)
\end{abstract}

Nós, pelo contrário, hoje podemos encontrar verdades e beleza nas palavras de um cozinheiro, de um balconista, de um garçom: essas independem de quem esteja sendo representado ou protagonizado, podemos ser atingidos do mesmo modo: eis que o Corcunda de Notre Dame, apesar de seu aspecto, parece-nos amável, torna-se belo, passível de nos produzir ná日os (pathos). Para os clássicos, tal representação seria impossível, ou seja, a personagem de Victor Hugo nunca os levaria à comoção, mas ao riso: já se faz sentir, no século XIX, uma grande transformação do modelo anterior que não se restringiria apenas ao campo temático (rompimento total dos estilos, por exemplo), nem mesmo à formação e representação imagéticas, mas ao próprio olhar e observação humanas.

\title{
A subjetividade e o reconhecimento do mundo
}

Esses não seriam mais os mesmos e o papel de destaque se deve à concretização da fotografia, termo/partida de uma onda de transformações verificadas ao longo daquele século e, quando dizemos um termo, queremos falar que ela foi o limiar de transformações processadas não só no século de seu aparecimento como também nos subsequentes, cujo resultado foi, inclusive, a mudança na forma de o ser humano ver a si mesmo e o mundo por que está rodeado. Essas transformações levariam, segundo Jonathan Crary, inclusive, ao rompimento do predomínio da visão renascentista, cujo vértice estava, segundo esse autor, no ponto de vista da câmara escura.

Por intermédio desta, parâmetro mimético por excelência, desconsiderava-se a interferência humana na produção imagética que se submetia, dessa forma, às rígidas leis físicas da refração e da reflexão, em cujo poder não competiria ao homem interferir, mas apenas aceitá-lo. Havia, portanto, uma relação de exterioridade entre o sujeito e seu objeto de observação, ou seja, o ato de ver é alijado do corpo físico do observador: 
At the same time, another related and equally decisive function of the camera was to sunder the act of seeing from the physical body of the observer, to decorporealize vision. The monadic viewpoint of the individual is authenticated and legitimized by the camera obscura, but the observer's physical and sensory experience is supplanted by the relations between a mechanical apparatus and a pre-given world of objective truth. (CRARY, 1992, p. 39-40)

Anteriormente, a própria autoridade da câmara escura não permitia ao homem interferir no processo físico da criação imagética devido às leis físicas da propagação da luz, afinal as imagens que se projetavam no fundo escuro da câmara eram decorrentes do efeito de leis naturais que independiam do corpo contingente e cambiante do homem. (Cf.: FERRAZ, 2005, p. 50)

Não obstante, a rigidez imputada, desde o Renascimento, à arte e o consequente emprego da matemática e das ciências exatas para explicar a formação imagética (conceitos de luz, refração, reflexão), novas ideias filosóficas começaram a modificar essa Weltanschauung racionalista já em finais do século XVIII; temos, como exemplo, a importância da subjetividade para o reconhecimento do mundo em que os homens estão inseridos. Essa busca pela subjetividade que vê, sente e interfere na visão como algo não meramente externo ao homem, pôde ser vista, inclusive, em Kant, em sua obra Crítica da razão pura (1787), quando afirma que

[...] nossa representação das coisas como nos são dadas [devem ser guiadas] [...] não por estas como coisas em si mesmas, mas que estes objetos, como fenômenos, muito antes se guiem pelo nosso modo de representação. (KANT, 1999, p. 40)

Ainda segundo o filósofo alemão, conhecemos o que é possível passar pelo crivo de nossa sensibilidade, logo pelo nosso olhar, sem o qual é, simplesmente, ignorado:

[...] nossa intuição não é senão a representação de fenômeno: que as coisas intuímos não são em si mesmas tal qual as que intuímos nem que suas relações são em si mesmas constituídas do modo como nos aparecem e que, se suprimíssemos o nosso sujeito ou também apenas a constituição subjetiva dos sentidos em geral, desapareceriam toda a constituição, todas as relações dos objetos no espaço e no tempo, e mesmo espaço e tempo. Todas essas coisas enquanto fenômenos não podem existir em si mesmas, mas somente em nós. [...] os objetos em si e separados de toda esta receptividade da nossa sensibilidade, permanece-nos inteiramente desconhecidos. Não conhecemos senão o nosso modo de percebê-los, o qual nos é peculiar e não tem que concernir necessariamente a todo ente, mas sim a todo homem. (ibidem, p. 83)

Crary demonstra-nos, metaforicamente, a importância da câmara escura no período anterior ao século XIX, como no Seiscentismo, utilizando-se de duas obras de um pintor muito conhecido do período, o holandês Jan van Vermeer, cujas telas $O$ astrônomo (1668) e O geógrafo (1668/69 - fig. 7) representam cada uma os estudiosos que as nomeiam. Vê-se cada um deles, absorto em seus afazeres, encerrados em seus ambientes de estudo, onde se veem objetos que traduzem seus ofícios: em um há um globo celeste; noutro cartas náuticas: 


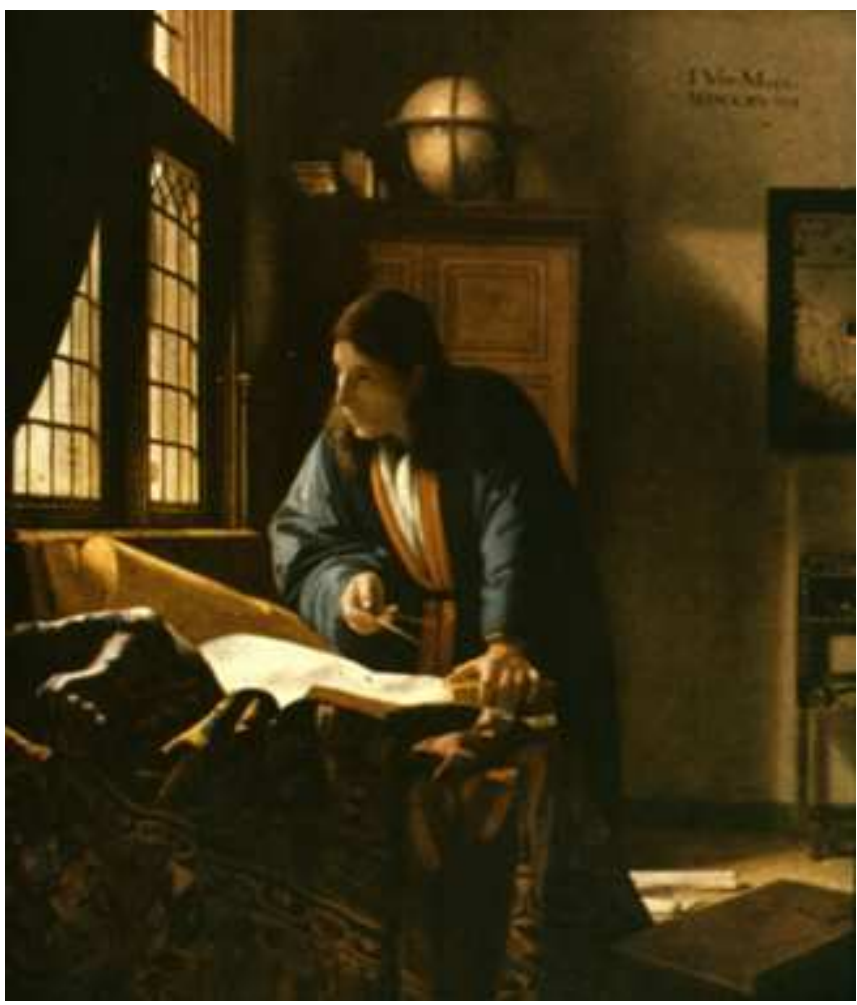

Figura 7 - O geógrafo, de Jan van Vermeer, 1668.

Each has his eyes averted from the aperture that opens onto the outside. The exterior world is known not by direct sensory examination but through a mental survey of its "clear and distinct" representation within the room, the somber isolation of these meditative scholars within their walled interiors is not in the least an obstacle to apprehending the world outside, for the division between interiorized subject and exterior world is a pre-given condition of knowledge about the latter. (CRARY, 1992, p. 46).

À continuação, Crary demonstra-nos a relação entre o mundo interno - o ambiente de estudo/trabalho - com o mundo externo - representado pelo globo, pelos mapas, pelas cartas náuticas -; como se as pinturas pretendessem evidenciar a reconciliação da função da câmara escura, cujo interior seria a interface entre aquilo que Descartes considerava como termos dissimilares: res cogitans e res extensa; esta seria o domínio da matéria; aquela, da mente, do espírito. Uma a visibilidade do mundo exterior, a outra como essa mesma é visualizada a partir da individualidade de cada um. Por meio da luz que entra no ambiente interno - à semelhança do orifício por onde a luz penetra no interior da câmara escura - o estudioso pode conhecer o mundo externo, representado por mapas, cartas, imagens, pelo globo, sem ter a necessidade de ter de sair de sua clausura: tem-se acesso, portanto, a uma projeção do mundo, interage-se com ele sem, contudo, poder interferir nele, sem poder modificá-lo, numa atitude passiva diante do deslumbramento do mundo formado internamente. Sua atitude é de mera contemplação, apesar de palpável, de real: está-se diante do mundo exterior representado pelo globo estelar, pelas cartas náuticas, pelos mapas; enfim, da 
res extensa, porém essa contemplação só é possível, porque sua mente interfere no processo, a res cogitans, daí a não reconciliação entre os dois termos cartesianos que, aparentemente, a câmara escura rompe:

The production of the camera is always a projection onto a two-dimensional surface - here maps, globes, charts, and images. Each of the thinkers, in a rapt stillness, ponders that crucial feature of the world, its extension, so mysteriously unlike the unextended immediacy of their own thoughts yet rendered intelligible to mind by clarity of these representations, by magnitudinal relations. (ibidem, p. 46)

Goethe, por sua vez, também põe em xeque - a partir da obra Zur Farbenlehre (1810) - essa relação de distanciamento entre o homem e o mundo proporcionada pela câmara escura, propondo uma experiência simples, a partir da qual se verá o esvaziamento do sistema e da عпıбrín (epistéme) clássicas que alijavam a imagem do corpo:

Let a room be made as dark as possible; let there be a circular opening in the windowshutter about three inches in diameter, which may be closed or not at pleasure. The sun being suffered to shine through this on a white surface, let the spectator from some little distance fix his eyes on the bright circle thus admitted. The hole being then closed, let him look towards the darkest part of the room; a circular image will now be seen to float before him. The middle of this circle will appear bright, colourless, or somewhat yellow, but the border will at the same moment appear red. (GOETHE, 1840, p. 16).

Goethe mostra-nos que ao se fechar o orifício da câmara, os olhos veem na escuridão, pois divisarão várias imagens de cores diversas, provenientes não mais dos raios luminosos externos ao corpo, mas a partir do próprio corpo:

After a time this red, increasing towards the centre, covers the whole circle, and at last the bright central point. No sooner, however, is the whole circle red than the edge begins to be blue, and the blue gradually encroaches inwards on the red. When the whole is blue the edge becomes dark and colourless. This darker edge again slowly encroaches on the blue till the whole circle appears colourless. The image then becomes gradually fainter, and at the same time diminishes in size. Here again we see how the retina recovers itself by a succession of vibrations after the powerful external impression it received. (ibidem, p. 16-17).

Observações demonstram que não é mais a física, nem a lógica matemática e externa ao homem que presidem a visão, mas o próprio olho com sua fisiologia inerente que percebe o mundo ele mesmo, não mais como uma realidade externa imposta, sem sua efetiva participação:

Quando a própria produção de imagens pode ser desvinculada de um "mundo" exterior, fixado, estável, seguro, desestabilizaram-se, simultaneamente, as certezas concernentes tanto ao sujeito quanto ao objeto; no mesmo gesto, os processos de percepção e conhecimento passam, necessariamente, a ser alvo de experimentação, observação, descrição e ciência. (FERRAZ, 2005, p. 50). 
Para isso, faz-se necessária a participação do eu-observador que participará, efetivamente, na construção imagética, não mais de forma passiva, mas ativamente, por isso Crary afirma, a partir dos conceitos abordados por Goethe, que:

The corporeal subjectivity of the observer, which was a priori excluded from the concept of camara obscura, suddently becomes the site on which an observer is possible. The human body, in all its contingency and specificity generates "the spectrum of another colour", and thus becomes the active producer of optical experience. (CRARY, op. cit., p. 69).

Vê-se, portanto, um conhecimento/desenvolvimento significativo da fisiologia óptica, pois, a partir do estereoscópio ${ }^{4}$, por exemplo, o corpo passa a ser um componente intrínseco da própria máquina, quando por meio do instrumento óptico a pessoa não só tem uma visão binocular como também tridimensional da imagem. Diante dessa participação do homem, seu ato de olhar deixa de ser apenas passivo, a de mero espectador da cena/imagem vinculada "à passividade e à mera assistência, conforme se pode constatar no modo como se concebe o espectador do teatro clássico" (Machado, 2002, p. 228); passando a ser ativo, a de observador, ou seja, "alguém que vê no âmbito de um conjunto de possibilidades, alguém que está constrangido por um sistema de convenções e limitações" (ibidem, p. 229). A imagem estereoscópica, portanto, rompe com a perspectiva renascentista a partir de um único ponto de fuga,

Por consequência, ela modifica o conceito tradicional de "ponto de vista", ou seja, aquela particular relação de um observador com o objeto de sua visão, em torno da qual a significação foi estabelecida durante séculos. Não havendo ponto de fuga ou ponto de vista únicos, não há também hegemonia de um código perspectivo unilocular, como aquele que norteou toda a história ocidental a partir do século XV. (ibidem, p. 230-231).

\section{O papel da fotografia na nova percepção}

É mister, nesse momento, retornar àquilo que foi dito em relação à paradoxalidade do rompimento dos gêneros pictórico e poético para que possamos dar prosseguimento a este estudo, cujo vértice é, precisamente, a fotografia. Poderíamos

\footnotetext{
${ }^{4}$ Instrumento óptico que permite ver efeitos de relevo em imagens planas, a partir de fotografias (ou de desenhos) obtidas do mesmo objeto, tiradas de posições ligeiramente diferentes, cuja separação pode ser semelhante à que existe entre os olhos, posssibilitando, portanto, uma visão binocular e a percepção da tridimensionalidade dos objetos. A imagem que se forma na retina de cada olho é plana, mas como há uma pequena diferença entre elas e os olhos estão separados uns 5 a 8 centímetros. O cérebro se encarrega de "fundir" essas duas imagens em uma só, resultando no efeito tridimensional. Esse efeito tridimentsional pode ser simulado, mesmo sem o aparelho, usando-se duas figuras planas, ligeiramente diferentes, como as que seriam projetadas em cada retina, separadamente. Só que, nesse caso, os próprios olhos devem se encarregar de "misturar" as imagens, antes de enviá-las ao cérebro. Para isso, é necessário fazer convergir os olhos de modo a obter uma imagem nas retinas que combine as duas imagens planas das figuras. Algumas pessoas, no entanto, têm dificuldades para isso, já que não conseguem fazer esse movimento forçado de "trocar os olhos". Nesses casos, o uso do esteresocópio resolve o problema, já que projeta uma imagem diferente em cada olho, dispensando a necessidade de fazê-los convergir à força.
} 
inferir que essa ruptura não se deu totalmente, mas à semelhança de um prévanguardismo, já que foi, num primeiro momento, somente uma mudança de direção. Para a concretização vanguardista, por exemplo, faz-se necessário um período de encetamento $^{5}$ (conforme visto nas figuras 3,4 e 5 ), indispensável para haver o rompimento - de forma abrupta e revolucionária (fig. 6) - com o status quo; possibilitando, a posteriori, à pintura conhecer, de forma mais profunda, seu objeto de estudo ou emprego - as cores, a luz, as sombras -; e à literatura, uma nova relação com as palavras, a sintaxe e a métrica. Isso possibilitou a ambas que explorasse, em si mesmas todas as possibilidades estéticas possíveis, inclusive utilizar-se de elementos da própria iconologia como, provavelmente, faz Dalí, não de uma forma impositiva, mas como paradigmas a serem utilizados.

Evidentemente, no século XIX, esse movimento foi incipiente, ainda não seria esse o momento que veríamos o rompimento total com os modelos antigos, pois o que se vislumbrou, efetivamente, foi o pouco tempo de liberdade que ambas as estéticas a escrita e a pictórica - tiveram uma em relação à outra, afinal assistimos, simplesmente, a uma troca de eixo com a entrada de um terceiro elemento que não só se imiscui em ambas como também as influencia que foi a fotografia. Dessa forma, não só o lugar da poesia em relação à pintura não ficou vago durante muito tempo, como também o inverso, a pintura enquanto modelo da poesia. (Cf. PRAZ, 1982, p. $4) .^{6}$

É possível verificar que, mesmo no século XIX, a fotografia foi tomando o papel que pertenceu à pintura em séculos anteriores, pois a nova técnica longe de se opor a toda tradição pictórica, não faz senão apostar em sua perpetuação, na medida em que petrifica os arquétipos que a sustentam. (MACHADO, op. cit. p. 150)

Mas, mesmo assim, seu espaço foi sendo conquistado e, à diferença do modelo anterior, não mais como um paradigma a ser seguido e emulado, mas como uma nova opção de retratar a natureza de forma, aparentemente, precisa e altamente mimética ${ }^{7}$, quando a TÉxun humana age sem a necessidade de mãos humanas, criando uma pintura técnica ou uma arte técnica por excelência ${ }^{8}$.

Portanto, esse deslocamento poesia/pintura $\rightarrow$ poesia/fotografia, seria uma consequência natural do avanço humano e do emprego de sua TÉxun, por isso devemos observar que na primeira relação (poesia/pintura), cujo princípio norteador

\footnotetext{
${ }^{5}$ Que corresponde, exatamente, ao período em questão, o século XIX, em relação às inovações concretizadas no início do século XX.

6 Assim diz Praz: "O grau de prestígio alcançado pela Pintura, graças aos grandes mestres italianos da Renascença, deu azo a que obtivesse uma vitória sobre sua arte irmã, a Poesia; testemunham-no os incansáveis esforços dos poetas de emular os pintores na sensualidade de suas descrições". (PRAZ, op. cit., p. 4)

7 Veremos que somente nos primórdios da fotografia isso aconteceu, pois se verificou depois a possibilidade de se retocar e modificar o "mimeticamente perfeito".

${ }^{8}$ Vale salientar que a fotografia absorve aspectos da composição imagética pictural como a iluminação, a disposição da(s) pessoa(s) dentro da moldura ou mesmo o termo enquadrar, termos e conhecimentos que os primeiros fotográfos já dominavam, afinal em sua grande maioria eram pintores, afinal "a câmara era [...] um mecanismo óptico complicado e só rendia imagens nítidas e significativas se fosse manobrada por um perito em representação visual; é por isso [...] que a produção fotográfica primitiva seguiu comodamente as determinações do gosto pictórico reinante" (Machado, op. cit., p. 31).
} 
era a $\mu i \mu \eta \sigma \zeta$, , empregavam-se iconologias, a imagem (pictórica e escultórica) estava submetida à tutela do $o_{y}$ os que as direcionava. Havia, dessa forma, uma via de mão única: das iconologias (incluindo os livros de emblemas) para a obra artística (pintura, escultura, poesia), ao artista - mero тعхviтns (technítes) - não cabia, portanto, criatividade, cujo conceito era-Ihe desconhecido;

na outra relação (poesia/fotografia) o gérmen mimético desaparece, apesar de a fotografia ser, a priori, mimética por excelência; empregam-se iconofotologias, no entanto essas não existem de per si como compilações a serem observadas, estudadas e/ou empregadas, mas como um acervo individual construído ao longo dos anos por uma pessoa, bem como por uma determinada comunidade em que esteja inserida. (Cf. BRANDÃO, 2010b, p. 94-97) Há, portanto, uma via de mão dupla: já que o artista pode partir tanto da natureza como de si mesmo, de seu próprio acervo iconofotológico, ou seja, das imagens fotográficas que permeiam sua memória. A escolha agora deixa de ser uma imposição, passando a depender de sua criatividade, de sua intenção e daqueles a quem pretende chegar.

Evidentemente que, nessas duas relações, tais princípios estendem-se também a seus respectivos leitores, ou seja, se tratarmos do modelo epistemológico em que o barroco estava inserido, os leitores do período tinham de ter acesso à chave cognitiva para que pudessem compreender as obras do período sem a qual seria impossível a apreensão do que seus autores pretendiam. Isso fica claro quando, em períodos ulteriores, tais obras - bem como seus autores - foram consideradas obscuras ou incompreensíveis: faltará, portanto, aos leitores de períodos históricos posteriores manuais para a sua compreensão.

\section{Referências}

AUERBACH, Erich. Mímese: a representação da realidade na literatura ocidental. São Paulo, Perspectiva, 2004.

BELTING, Hans. Imagen y culto: una historia de la imagen anterior a la edad del arte. Madrid, Akal, 2009.

BRANDÃO, Antônio Jackson S. Iconofotologia do Barroco alemão. Tese de doutorado apresentada à Universidade de São Paulo, 2008.

. "O gênero emblemático". In Travessias 7, Cascavel, 2009.

"A imagem nas imagens". In Lumen et Virtus, São Paulo, 2010a.

"Da pintura à fotografia: o encetamento iconofotológico". In Lumen et

Virtus, São Paulo, 2010b.

CRARY, Jonatahn. Techniques of the observer: On vision and modernity in the nineteenth century. Cambridge \& London, MIT Press, 1992.

FARINACCIO, Pascoal. A questão da representação e o romance brasileiro contemporâneo, 2004, Tese (Teoria Literária), Unicamp, Campinas. 
FERRAZ, Maria Cristina Franco. "Tecnologias, memória e esquecimento: da modernidade à contemporaneidade", in Revista FAMECOS, Porto Alegre, 49-57, 2005. GOETHE, Johan W. von. Theory of Colours. London, John Murray, 1840.

GONÇALVES, Márcia C. F. "A recusa da teoria da mímesis pelas teorias estéticas na virada dos séculos XVII e XIX e suas consequências". In DUARTE, Rodrigo. Figueiredo, Virgínia (org.) Mímese e expressão. Belo Horizonte, Ed. UFMG, 2001.

ISER, Wolfgang. O ato de leitura: uma teoria do efeito estético. Vol. 2. São Paulo, Ed. 34, 1999.

KANT, Immanuel. Os pensadores: Kant. São Paulo, Nova Cultural, 1999.

LESSING, Gotthold E. Laocoonte ou sobre as fronteiras da pintura e da poesia. São Paulo, Iluminuras, 1998.

MACHADO, Arlindo. A ilusão especular: introdução à fotografia. São Paulo, Brasiliense, 1984.

PANOFSKY, Erwin. Significado nas artes visuais. São Paulo, Perspectiva, 2001.

PRAZ, Mário. Literatura e artes visuais. São Paulo, Cultrix, 1982.

RIPA, Cesare. Iconología (Prólogo de Adita Allo Manero). Tomo I. Madrid, Akal, s/d. Iconología. Tomo II. Madrid, akal, 1987.

SCHØLLHAMMER, Karl. E. "Regimes representativos da modernidade". In Alceu, v. I, n. 2, Rio de Janeiro, 28-41, 2001.

\section{Title}

Rupture of the Epistemological Mimetic Model

\section{Abstract}

Mimesis as epistemological model reached its apogee in the 17th century and it feels into decline in the following centuries. With its disruption, lost the models of representation that also permeated Western culture for centuries, and from the $19^{\text {th }}$ century, the subjectivity takes the leading role in art. More than a change in the perception of art, there was a change in perception of the world that surrounds the human being, whose great influence was due to the photography.

\section{Keywords}

Mimesis. Iconology. Representation. Baroque. Iconophotology.

Recebido em 16.06.2011. Aprovado em 11.07.2011. 